\title{
SISTEMA DE GESTÃO INTEGRADO: A ATUAÇÃO DO SECRETÁRIO EXECUTIVO
}

\section{INTEGRATED MANAGEMENT SYSTEM: THE ROLE OF THE EXECUTIVE SECRETARY PROFESSIONALS}

\section{Marcilia Helena de Sousa Mascarenhas}

Especialista em Secretariado Executivo - FACINTER

marcilia@labsar.coppe.ufrj.br

\section{Fernando A. Miranda Sepulveda}

Doutor em Engenharia de Produção pela Universidade Federal do Rio de Janeiro - UFRJ

\section{Elisângela Schastai D'Assumpção}

Especialista em Logística Empresarial e Processo Pedagógico no Ensino Superior pela Pontifícia Universidade Católica do Paraná - PUCPR 


\section{RESUMO}

Considerando o avanço da globalização e a alta competitividade entre as empresas, a necessidade de melhoria contínua é uma exigência do mercado. A implementação do Sistema de Gestão Integrado (SGI) viabiliza qualificar a empresa e capacitar seus participantes para ter maior produtividade, com menor custo, preservando a saúde dos seus funcionários e o meio ambiente. O SGI envolve a aplicação de métodos para atender aos requisitos dos Sistemas da Qualidade, de Gestão Ambiental, Sistema de Segurança e Saúde no Trabalho e de Responsabilidade Social, que são determinados por normas brasileiras e/ou internacionais. Neste contexto observam-se as mudanças no perfil do profissional de secretariado executivo, tornando-o mais qualificado e atuando diretamente na gestão de competências e assessorando seus gestores nos processos de modo a garantir resultados satisfatórios para a organização. 0 presente artigo aborda por meio de pesquisa bibliográfica os conceitos dos diversos sistemas de gestão e a importância da atuação do profissional de secretariado executivo na assessoria ao gestor na aplicação do Sistema de Gestão Integrado.

Palavras-chave: Sistemas de gestão; Secretário Executivo; SGI. 


\section{ABSTRACT}

Considering the advance of globalization and high competition between the companies, the need of continuous improvement is a requirement of the market. The implementation of the System of Management Integrated (SGI) enables the company to and qualify its participants to have higher productivity, with smaller cost, preserving the health of its employees and the environment. The SGI involves the application of approaches for attend to the requirements of the Quality Systems, Environmental management, System of Security and Health in the Work and Social Responsibility, which are determined by Brazilian and/or international standards. In this context it is possible to see the changes in the profile of the executive secretarial professional, making him more qualified and acting straightly in the management skills and assisting in its management processes to ensure satisfactory outcomes for the organization. The present article covers through bibliographical research the concepts of the various management systems and the importance of the action of the executive secretarial professional assistance to the manager in the implementation of the System of Management Integrated.

Keywords: Systems of management; Executive secretary; SGI. 


\section{INTRODUÇÃO}

Este artigo descreve os conceitos de sistema de gestão integrado (gestão de qualidade, de segurança, de saúde no trabalho e de meio ambiente), fazendo a relação com a atuação do secretário executivo, e identifica sua participação nos processos.

Para uma organização ser considerada excelente é necessário possuir padrões de qualidade de acordo com normas brasileiras e/ou internacionais. $\mathrm{O}$ Sistema de Gestão Integrado (SGI) envolve a elaboração e implementação de métodos para atender aos requisitos dos Sistemas de Gestão Ambiental, da Qualidade, de Segurança e Saúde no Trabalho e de Responsabilidade Social. O profissional de secretariado precisa ter conhecimento, treinamento e envolvimento em todos os processos para melhor assessorar seu gestor dentro da organização. É por meio desta assessoria com qualidade que o profissional de secretariado vai facilitar o trabalho do gestor, cuidando do planejamento, comunicação e feedback dos colaboradores.

Por meio de pesquisa bibliográfica este artigo faz um estudo dos conceitos, características e importância do Sistema de Gestão Integrado (SGI) e pretende identificar e sinalizar a importância da participação e atuação direta do secretário executivo nos processos.

\section{SISTEMA DE GESTÃO INTEGRADO}

Para Wagner e Hollenbeck (1999 apud SEPULVEDA, 2009, p. 42) as constantes mudanças ocorridas nos processos de gestão, nas metodologias e nas ferramentas, devido aos cenários globalizados e a corrida por vantagens competitivas, pedirão novas atitudes das organizações, uma vez que estes deverão saber redirecionar suas estratégias, transformando decisões e planos, garantindo-Ihes um diferencial, tendo sempre em vista a qualidade.

Segundo Boschetti (2005 apud SEPULVEDA, 2009, p. 18) o Sistema de Gestão Integrado nasce da necessidade de o mercado integrar as novas formas

Revista de Gestão e Secretariado, São Paulo, v. 2, n. 1, p.177-192, jan./jun. 2011. 
Marcilia Helena de Sousa Mascarenhas; Fernando A. Miranda Sepulveda \& Elisângela Schastai D'Assumpção

de gestão de negócios: qualidade, meio ambiente, saúde e segurança no trabalho.

International Organization for Standardization (ISO) é uma federação mundial composta por entidades de normalização de mais de 110 países, fundada em 1947, para promover o desenvolvimento de normas internacionais na indústria, comércio e serviços. No Brasil, a Associação Brasileira de Normas Técnicas (ABNT) é a representante da ISO com direito a voto no fórum internacional de normalização (CHAIB, 2005, p. 13).

O Sistema de Gestão Integrado é baseado na aplicação das normas internacionais: ISO 14.001:2004 (Sistema de Gestão Ambiental), 9.001:2000 (Sistema de Gestão da Qualidade), OHSAS 18.001:2007 (Sistema de Gestão de Segurança e Saúde no Trabalho) e a norma brasileira 16.001:2004 (Sistema de Responsabilidade Social).

O sistema de gestão da qualidade provê a estrutura onde os processos são controlados para atender objetivos de negócios e capaz de acomodar novos requisitos tais como gestão ambiental (MAXWELL; HILLE, 1995 apud SEPULVEDA 2009, p. 45).

De acordo com Viterbo Júnior (1998, p. 15 apud CHAIB, 2005, p. 4), os objetivos básicos do sistema de gestão são:

\footnotetext{
de aumentar constantemente o valor percebido pelo cliente nos produtos ou serviços oferecidos, o sucesso no segmento de mercado ocupado (através da melhoria contínua dos resultados operacionais), a satisfação dos funcionários com a organização e da própria sociedade com a contribuição social da empresa e o respeito ao meio ambiente.
}

Para Boschetti (2005 apud SEPULVEDA, 2009, p. 23) as vantagens da implantação de um SGI são:

- fazer com que as ações da gestão ocorram numa base sistemática (regular);

- garantir a conscientização e a comunicação em nível proporcional aos riscos;

- apoiar-se nas auditorias (internas e externas) como mecanismo de manutenção e melhoria;

- propiciar uma ferramenta para a empresa gerenciar Qualidade, Meio Ambiente, Segurança e Saúde no Trabalho;

Revista de Gestão e Secretariado, São Paulo, v. 2, n. 1, p.177-192, jan./jun. 2011. 
- gerenciar preventivamente e de forma abrangente;

- organizar e manter a memória tecnológica da empresa.

De Cicco (2000) ainda cita como benefícios concretos: redução de custos, simplificação da documentação (manuais, procedimentos e registros), atendimento estruturado e sistematizado à legislação.

Segundo Soler (2002 apud CHAIB, 2005, p. 27), existem diversas formas de implantação de SGI, que dependem de características próprias da organização que irá implantá-los. $\mathrm{O}$ autor ainda ressalta que o atendimento às necessidades não implica necessariamente um processo formal de certificação, podendo estar restrito apenas à melhoria de processos e produtos da organização.

Conforme Soler (2002 apud CHAIB, 2005, p. 29), o principal argumento para a integração dos processos de gestão é o efeito positivo que um SGI pode ter sobre os funcionários. Ele relata que a sinergia gerada tem levado as organizações a atingir melhores níveis de desempenho, com custo global menor.

\subsection{Sistema de Gestão da Qualidade - ISO 9.001:2000}

Segundo Boschetti (2001 apud SEPULVEDA, 2009, p. 11) a Qualidade vem-se tornando cada vez mais uma ferramenta estratégica para as organizações que

buscam um diferencial competitivo, por meio da demonstração da capacidade de gestão eficaz sobre os dados gerados, através da implantação dos novos conceitos e princípios, e a proatividade na tomada de decisões gerenciais objetivas e diferenciada.

O Sistema de gestão da qualidade é regulamentado pela norma internacional ISO 9001:2000 que se baseia na aplicação e gestão de um sistema de processos para aumentar a produtividade e a satisfação dos clientes e monitorar as atividades da organização.

De acordo com Pessoa (2007 apud PESSOA e SILVA, 2009) o ciclo PDCA (Planejar-Fazer-Checar-Agir) é uma sequência de atividades que são percorridas de forma cíclica para melhorar os resultados e/ou atingir as metas

Revista de Gestão e Secretariado, São Paulo, v. 2, n. 1, p.177-192, jan./jun. 2011. 
Marcilia Helena de Sousa Mascarenhas; Fernando A. Miranda Sepulveda \& Elisângela Schastai D'Assumpção

estabelecidas. Esta metodologia é aplicada em todos os processos do Sistema de gestão da qualidade e segue os seguintes passos:

- planejar - estabelecer missão, visão, objetivos, procedimentos e processos (metodologia);

- fazer - realizar, executar as atividades;

- checar - monitorar e avaliar periodicamente os resultados;

- agir - agir de acordo com o avaliado e relatórios, aprimorando a execução e corrigindo eventuais falhas. (PESSOA e SILVA, 2009).

A norma ISO 9.001:2000, conforme Boschetti (2001 apud SEPULVEDA, 2009, p. 12) se baseia em oito princípios de gestão:

- foco no cliente - entender e satisfazer suas necessidades;

- liderança - necessária para promover a unidade de objetivos e direção;

- envolvimento das pessoas - cooperação, envolvimento e motivação das pessoas;

- abordagem por processos - os recursos e atividades são tratados como processos;

- abordagem sistêmica para a gestão - os processos se relacionam entre si de modo a constituírem sistemas;

- melhoria contínua - a partir de ações de correção e de prevenção, busca-se a excelência nos produtos e processos;

- abordagem factual para a tomada de decisões - decisões eficazes são tomadas com base na análise dedutiva de dados e informações;

- benefícios mútuos nas relações com fornecedores - uma relação mutuamente proveitosa aumenta a habilidade de agregar valores.

Boschetti (2001 apud SEPULVEDA, 2009, p. 13) cita os benefícios advindos da aplicação destes princípios:

- maior capacidade de análise para tomada de decisão e de identificar oportunidades de melhorias;

- respostas mais flexíveis e rápidas às oportunidades oferecidas pelo mercado, bem como as oportunidades internas advindas de um monitoramento estruturado e melhoria da comunicação interna;

- maior entendimento dos objetivos e metas por parte das pessoas, bem como do seu papel dentro da organização;

- custos mais baixos e ciclos de tempo mais curtos para executar as atividades;

- maior integração e adaptação dos processos que melhor contribuem para a obtenção dos resultados.

Revista de Gestão e Secretariado, São Paulo, v. 2, n. 1, p.177-192, jan./jun. 2011. 


\subsection{Sistema de Gestão de Segurança e Saúde no Trabalho - ohsas 18.001:2007}

Segundo Boschetti (2005 apud SEPULVEDA, 2009, p. 15) a OHSAS 18.001:2007 permite à empresa atingir, controlar e melhorar o nível de desempeno da Saúde e Segurança do Trabalho por ela mesma estabelecido.

Boschetti (2005 apud SEPULVEDA, 2009, p. 16) reporta que a norma se aplica a empresas de qualquer porte e ramo de atividade, que queira adotar uma abordagem proativa para a gestão de riscos à saúde no trabalho e à segurança. O autor cita as melhorias com a aplicação da norma OHSAS 18.001:2007:

- melhoria na cultura de segurança, reduzindo os acidentes na produção;

- demonstração do compromisso com a proteção do seu pessoal e dos ativos fixos;

- promoção das comunicações internas e externas.

Para Guerra e Mitidieri (2010), o sistema de gestão de saúde e segurança no trabalho está intimamente relacionado à gestão ambiental. Os autores citam a Resolução do Conselho Nacional do Meio Ambiente (CONAMA), número 001/86, que considera como impacto ambiental qualquer alteração das propriedades físicas, químicas e biológicas do meio ambiente que, direta ou indiretamente, afetam a saúde, a segurança e o bem-estar da população, incluindo o trabalhador.

\subsection{Sistema de Gestão Ambiental - ISO 14.001:2004}

As organizações competitivas estão preocupadas com a preservação do meio ambiente e procuram demonstrar seu compromisso por meio da aplicação da norma internacional ISO 14.001:2004.

Segundo Billig \& Camilato (2009), o sistema de gestão ambiental consiste em um conjunto de atividades planejadas realizadas pela empresa para gerir ou administrar sua relação com o meio ambiente. Através deste sistema, $a$ empresa se mobiliza para controlar os impactos das atividades, produtos e

Revista de Gestão e Secretariado, São Paulo, v. 2, n. 1, p.177-192, jan./jun. 2011. 
Marcilia Helena de Sousa Mascarenhas; Fernando A. Miranda Sepulveda \& Elisângela

Schastai D'Assumpção

serviços no meio ambiente, buscando atingir e demonstrar um desempenho ambiental correto.

Para Boschetti (2005 apud SEPULVEDA, 2009, p. 14), com a implantação desta norma, a organização tem alguns benefícios como melhoria no controle de custos por meio da conservação de matéria-prima e energias e redução do risco de acidentes.

Segundo a ISO 14.001, o Sistema de Gestão Ambiental é definido como parte do Sistema de Gerenciamento Global que inclui:

a estrutura organizacional, o planejamento de atividades, responsabilidades, práticas, procedimentos, processos e recursos para o desenvolvimento, implementação, alcance, revisão e manutenção da política ambiental. (CHAIB, 2005, p. 14).

A certificação de sistemas de gestão ambiental permite concluir que a organização possui uma política ambiental e que a está implementando em conformidade com os requisitos da norma referencial. (CHAIB, 2005, p. 14).

\subsection{Sistema de Responsabilidade Social - NBR 16.001:2004}

Para Pinto (2008), Responsabilidade Social poderia ser definida como o reconhecimento de uma empresa de que suas ações precisam considerar os impactos, diretos e indiretos, causados ao meio ambiente e às pessoas.

Atualmente, a sociedade preocupa-se em consumir produtos e serviços advindos de organizações com comportamento ético, comprometidas com a ordem social e ambiental. A norma NBR 16.001:2004 foi criada a partir de requisitos internacionais para a gestão com responsabilidade social.

Segundo Pinto (2008), em estudo recente, a Universidade São Paulo (USP) identificou que a certificação socioambiental tem contribuído para diminuir o desmatamento; recuperar áreas de conservação; diminuir o uso de agrotóxicos; melhorar as condições de saúde e segurança de trabalhadores e diminuir as fontes de poluição.

De acordo com Guerra e Mitidieri (2010), para o Instituto Ethos de Empresas e Responsabilidade Social (ETHOS), a empresa é socialmente responsável quando vai além da obrigação de respeitar as leis, pagar impostos e

Revista de Gestão e Secretariado, São Paulo, v. 2, n. 1, p.177-192, jan./jun. 2011. 
observar as condições adequadas de segurança e saúde para os trabalhadores, fazendo isso por acreditar que assim será uma empresa melhor e estará contribuindo para a construção de uma sociedade mais justa.

\section{A HISTÓRIA DO SECRETÁRIO EXECUTIVO}

A profissão surgiu nas civilizações antigas, pelos escribas que dominavam a escrita. (PORTELA; SCHUMACHER, 2006, p. 16). O termo Escriba em hebraico é originado de Sôpher (Contar) (NONATO JÚNIOR, 2009, p. 81).

Nonato Júnior (2009) relata que várias profissões têm em sua história referências do escriba. Mas que, no caso do Secretariado, a referência é muito intensa, pois a principal característica das atividades realizadas pelo escriba era o ato de assessorar.

A palavra secretário vem de Secretarium - significa lugar retirado, conselho privado; Secretum - segredo. (PORTELA; SCHUMACHER, 2006, p. 16).

Para Portela e Schumacher (2006), a evolução da profissão teve vários marcos no mundo: Na Idade Média era restrita aos monges, em 1760, com a Revolução Industrial, era exercida quase que exclusivamente por homens. Com as Guerras Mundiais de 1914-1918 e 1939-1945 as mulheres ingressaram na profissão e passam a ser reconhecidas.

No Brasil, a profissão começa a ser percebida nos anos 1950. Portela e Schumacher (2006) citam que, em 1970, foi criada a Associação das Secretárias do Rio de Janeiro, que foi a primeira associação civil.

Nonato Júnior (2008b apud NONATO JúNIOR, 2009, p. 90) comenta que, na segunda metade do século $X X, O$ crescimento dos profissionais de secretariado ocorreu em consonância com o desenvolvimento da tecnologia e dos paradigmas da ciência.

Em 20 de setembro de 1977 foi criada a Lei no. 1.421, que instituiu o dia 30 de setembro como o dia nacional da Secretária, em comemoração a Lílian Scholes, filha do criador da máquina de escrever - Charles Scholers.

O primeiro documento oficial que reconheceu o Secretariado e regulamentou suas atribuições foi a Lei no. 6.556/78, de 5 de setembro de 1978 .

Revista de Gestão e Secretariado, São Paulo, v. 2, n. 1, p.177-192, jan./jun. 2011. 
Em 30 de setembro de 1985 foi sancionada a Lei no. 7.377 que dispõe sobre a profissão de Secretário. A lei n. 9.261 de 10 de janeiro de 1996 alterou a redação da Lei no. 7.337, de 30/9/85. O Código de Ética do Profissional de Secretariado foi publicado no Diário Oficial da União de 07 de julho de 1989.

\section{O PERFIL DO SECRETÁRIO EXECUTIVO}

Enquanto nos anos 1950 o secretário tinha como atividades a taquigrafia, datilografia, atendimentos telefônicos e arquivo, nos anos 1980 percebe-se uma valorização da profissão, quando o secretário passa a atuar em conjunto com as chefias. Com a chegada da era da informática e da qualidade, o perfil do secretário executivo se transforma. Ele passa a ser cogestor, empreendedor e assessor dos seus gestores. Suas competências são mais visualizadas e sua participação nas decisões da empresa mais atuante. Ele passa a ser um facilitador e mediador entre seus pares e a direção da organização, cuidando da relação interpessoal e comunicação dos grupos sociais da organização.

Portela e Schumacher (2006) identificam o novo perfil do secretário como:

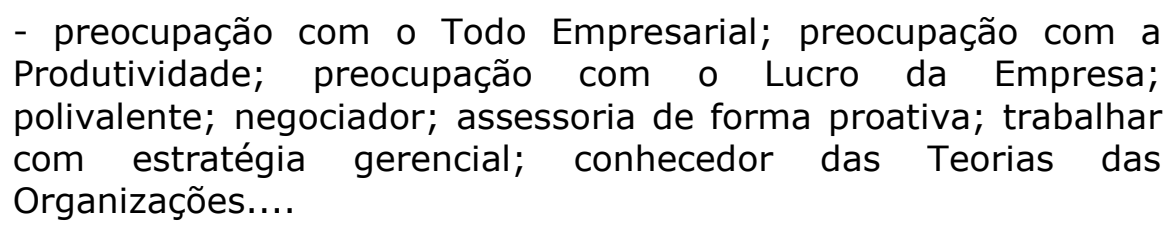

Segundo Veiga (2007), o profissional de secretariado ideal deve ter uma visão global da organização, bem como estar comprometido com a missão da organização e o resultado do trabalho.

De acordo com o Código de Ética, publicado no Diário Oficial da União de 7 de julho de 1989, constituem-se deveres fundamentais dos Secretários, conforme Artigo $5^{\circ}$ do Capítulo III:

... d) operacionalizar e canalizar adequadamente o processo de comunicação com o público;... f) procurar informar-se de todos os assuntos a respeito de sua profissão e dos avanços tecnológicos,

Revista de Gestão e Secretariado, São Paulo, v. 2, n. 1, p.177-192, jan./jun. 2011. 
que poderão facilitar o desempenho de suas atividades; [...] (PORTELA; SCHUMACHER, 2006, p. 24).

Segundo o Capítulo VI, Artigo $10^{\circ}$ do Código de Ética, das relações com a Empresa compete ao Profissional no pleno exercício de suas atividades:

a) identificar-se com a filosofia empresarial, sendo um agente facilitador e colaborador na implantação de mudanças administrativas e políticas; b) agir como elemento facilitador das relações interpessoais na sua área de atuação; c) atuar como figura-chave no fluxo de informações desenvolvendo e mantendo de forma dinâmica e contínua os sistemas de comunicação. (PORTELA; SCHUMACHER, 2006, p. 25).

A Lei no. 7.377 dispõe sobre as atribuições do Secretário Executivo, conforme artigo 40:

I- planejamento, organização e direção de serviços de secretaria;

II- assistência e assessoramento direto a executivos;

III- coleta de informações para a consecução de objetivos e metas de empresas; ... (VEIGA, 2007, p. 26).

Conforme Nonato Júnior (2009, p. 154), o Secretariado, enquanto profissão de ampla atuação, vem levando as práticas das assessorias a relações conceituais principalmente com:

- administração (quando as assessorias pesquisam e desenvolvem ideias que fazem avançar o trabalho dos gestores e das organizações);

- as Ciências da Informação (ao criar novas possibilidades de utilização dos recursos informacionais, sob o prisma do trabalho secretarial);

- Linguística e a Comunicação (nos estudos com línguas estrangeiras aplicadas aos negócios, comunicação gerencial e redação de língua materna para assessores);

Para Carvalho e Grisson (2002, p. 452), atualmente os profissionais de secretariado executivo buscam ferramentas para

Revista de Gestão e Secretariado, São Paulo, v. 2, n. 1, p.177-192, jan./jun. 2011. 
administrar eficazmente o tempo; aplicam as funções gerenciais (planejamento, organização, controle e direção); dão ênfase ao relacionamento com os clientes (internos e externos); valorizam os princípios de um sistema de comunicação; possuem habilidade para o trabalho em equipe na busca de sinergia; [...] procuram obter uma visão geral da cultura da organização; [...] acompanhando a evolução científica e tecnológica.

Podemos observar que, hoje, o profissional de secretariado está tão comprometido com os objetivos da empresa, que consegue visualizar e resolver os imprevistos de forma muito mais ampla, com consciência e responsabilidade, atuando como facilitador de processos e assessor direto do gestor, obtendo resultados positivos e a satisfação dos clientes.

\section{A ATUAÇÃO DO SECRETÁRIO EXECUTIVO NO SISTEMA DE GESTÃO}

O Sistema de Gestão Integrado (SGI) é a combinação de processos das gestões da qualidade, segurança, saúde no trabalho e meio ambiente, com o objetivo de tornar a organização mais competitiva, eficiente, com custos reduzidos. A atuação do secretário executivo nesses processos é essencial para a melhoria do sistema de informação, assessorar os gestores na gestão dos processos e integração das equipes para tornar a empresa competitiva.

A participação do Secretário Executivo nos processos de gestão está diretamente relacionada à assessoria de seu gestor. Em todos os sistemas de gestão é importante o conhecimento, envolvimento e monitoramento dos procedimentos por parte do secretário executivo.

Observa-se a atuação do secretário executivo na gestão de qualidade através da participação proativa e feedback dos colaboradores para direção da organização, tendo como resultados o aumento de competitividade, do moral do pessoal, redução de desperdícios e melhor conscientização de oportunidades de melhorias.

Carvalho e Grisson (2002, p. 453) afirmam que este profissional utiliza sua sensibilidade para

Revista de Gestão e Secretariado, São Paulo, v. 2, n. 1, p.177-192, jan./jun. 2011. 
Diagnosticar situações e buscar a capacidade de organização; a habilidade em lidar com modelos de gestão inovadora; gerenciar projetos e referenciar o estudo de viabilidade para sua execução; atuar em todas as áreas concernentes à profissão, tanto na organização, no planejamento, na administração, no assessoramento e na consultoria e nos vários níveis das empresas públicas e privadas.

A participação do Secretário Executivo na elaboração dos métodos e implementação do sistema de gestão integrado, capacita-o para identificar oportunidades de melhoria contínua da organização e - através do acompanhamento direto do sistema de comunicação interna e externa da organização, planejamento e controle de documentação e controle de registros e auditorias internas - facilitar e identificar ações preventivas e corretivas e assegurar o sucesso da organização.

Pela atuação do profissional de secretariado executivo, como mediador e usando os diversos sistemas de gestão é possível promover a satisfação e segurança dos clientes internos e externos, valorização das pessoas a partir do incentivo profissional e ambiente de trabalho saudável na organização.

\section{CONCLUSÃO}

O Sistema de Gestão Integrado é uma ferramenta importante para melhor posicionar a organização no mercado. Por meio da implementação e integração e gestão de diversas áreas, é possível qualificar a organização e torná-la mais produtiva com menos custos. Com a implantação do sistema de gestão integrado busca-se aumentar o valor percebido pelos clientes, a satisfação dos funcionários da organização e aprovação da sociedade quanto à participação social da empresa no respeito ao meio ambiente.

Com o aumento de competitividade e ofertas de mercado, o profissional de secretariado executivo está revendo e aprimorando suas competências nas diversas gestões. Dentro desta realidade, é possível entender o profissional de secretariado executivo como coparticipante na gestão de processos e responsável por contribuir nas tomadas de decisões da organização. Devido ao perfil polivalente e multifuncional este profissional é capaz de ser flexível, atuante e mediador nas relações organizacionais, atuando como facilitador dos

Revista de Gestão e Secretariado, São Paulo, v. 2, n. 1, p.177-192, jan./jun. 2011. 
Marcilia Helena de Sousa Mascarenhas; Fernando A. Miranda Sepulveda \& Elisângela Schastai D'Assumpção

processos junto aos clientes internos e externos, criando assim vantagens competitivas sustentáveis.

\section{REFERÊNCIAS}

BILLIG, Osvaldo Alencar; CAMILATO, Sérgio Paulo. Sistema de gestão integrada de qualidade, segurança, meio ambiente e saúde. FTEC Faculdades. Revista Eletrônica. 2009. Disponível em: www.ftec.com.br/empresajr/revista/autor/pdf/osvaldo1.pdf. (Acesso em: 26 mai. 2011).

BSI. $O$ que é ISO 9.001:2000? São Paulo. Disponível em: http://www.oficinadanet.com.br/apostilas/detalhe/529/o que e iso 90012000. ttp://translate.googleusercontent.com/translate c?hl=pt-

BR\&langpair=en|pt\&rurl=translate.google.com.br\&u=http://www.bsibrasil.com.b r/\&usg=ALkJrhgFHpQXzmVgW YUU-Wftbjk51SSOw. (Acesso em: 16 maio 2011).

CARVALHO, Antonio Pires de \& GRISSON, Diller. (Org.). Manual do secretariado executivo. 5. ed. Ver. e atual. São Paulo: D'Livros, 2002. 572 p.

CHAIB, Erick Brizon D'Angelo. Proposta para implementação de Sistema de Gestão Integrada de Meio Ambiente, Saúde e Segurança do Trabalho em empresas de pequeno e médio porte: Um estudo de caso da indústria metalmecânica. Rio de Janeiro, 2005, 126 p. COPPE/UFRJ, M. Sc, Planejamento Energético, 2005, Tese - Universidade Federal do Rio de Janeiro.

DE CICCO, Francesco. Sistemas Integrados de Gestão, agregando valor aos sistemas ISO 9.000. São Paulo: QSP - Centro da Qualidade, Segurança e Produtividade para o Brasil e América Latina, 2000. Disponível em: <http://www.qsp.org.br/artigo.shtml>. Acesso em 17 maio 2011.

GUERRA, Marco Aurélio d'Almeida \& MITIDIERI FILHO, Cláudio Vicente. Sistema de Gestão Integrada em construtoras de edifícios: como planejar e implantar um SGI. São Paulo: Pini, 2010.

ONONATO JÚNIOR, Raimundo. Epistemologia e teoria do conhecimento em secretariado executivo: a fundação das ciências da assessoria. Fortaleza: Expressão Gráfica, 2009.

PESSOA, Gerisval Alves SILVA, Maria José Nogueira da. Aplicação do PDCA: redução do índice de reclamações de clientes. 2009. Disponível em: $<$ http://www.ebah.com.br/content/ABAAABB6wAG/aplicacao-pdca>. (Acesso em: 19 maio 2011).

Revista de Gestão e Secretariado, São Paulo, v. 2, n. 1, p.177-192, jan./jun. 2011. 
PINTO, Luiz Fernando Guedes. Responsabilidade socioambiental. Responsabilidadesocial.com, ed. 119, ano 8, 20 set. 2008. Entrevista concedida a Cynthia Ribeiro. Disponível em: <http://www.responsabilidadesocial.com/article/article view.php?id=709>. (Acesso em: 17 maio 2011).

PORTELA, Keyla Christina Almeida \& SCHUMACHER, Alexandre José. Ferramentas do Secretário Executivo. São Paulo: Viena, 2006.

SANTOS, Gisele do Rocio Cordeiro Mugnol; MOLINA, Nilcemara Leal \& DIAS, Vanda Fattori. Orientações e dicas práticas para trabalhos acadêmicos. Curitiba: Ibpex, 2007.

SEPULVEDA, Fernando Antônio Miranda. Sistema de Gestão Integrado para Micros e Pequenas Empresas (MPEs) no "Business to Business". Tese (Doutorado em Engenharia de Produção) - Universidade Federal do Rio de Janeiro, Rio de Janeiro, 2009. 145 p.

VEIGA, Denise Rachel. Guia de Secretariado - técnicas e comportamento. São Paulo: Érica, 2007. 